$(\mathrm{HR}=0.41, \quad 95 \% \mathrm{CI} \quad 0.18-0.95 ; \quad P=0.039) \quad$ comparing with other therapy combination. In the rectum, combining chemotherapy, radiotherapy, and primary surgery in non-metastatic patients will increase the risk of death $(\mathrm{HR}=2.11$, 95\% CI 1.14-4.00; $P=0.022$ ). Pooling all patients received metastatic sites resection and comparing with the reference group, metastatic sites resection in GI-NEC will bring survival benefits ( $\mathrm{HR}=0.42$, 95\%CI 0.19-0.93; $P=0.033)$.

Conclusions GI-NECs have different treatment patterns. Primary sites resection should be the basic treatment choices for GI-NECs. Chemotherapy should be cautious, especially in non-metastatic patients and considered more biological characteristics of NECs (eg: Ki-67) before using it. Patients with distant metastasis can benefit from metastatic sites resection.

\section{IDDF2020-ABS-0079 A SINGLE CENTRE RETROSPECTIVE STUDY OF INPATIENT MANAGEMENT IN ACUTE LOWER GASTROINTESTINAL BLEEDING}

Wilson Siu*, Yusuke Onishi, Wamedh Taj-Aldeen, Balasubramaniam Vijayan. Department of Digestive Disorders, Aberdeen Royal Infirmary, UK

\subsection{6/gutjnl-2020-IDDF.65}

Background Acute lower gastrointestinal bleeding (ALGIB) is a common presenting condition in hospital with an estimated incidence of $33-87 / 100000$. Recent national audit in the United Kingdom has shown that the bleeding stops in the majority of the cases without any intervention. In this retrospective study, we aim to describe patient characteristics and to identify factors that predict clinical outcomes.

Methods Haemodynamically unstable patients with ALGIB are admitted to the medical high dependency unit (MHDU) at Aberdeen Royal Infirmary for monitoring. Patients with a primary diagnosis of ALGIB between 01/05/2015 to 15/09/2017 were identified from the MHDU database. Patients who presented with haematemesis or had upper gastrointestinal (UGI) bleeding found at esophagogastroduodenoscopy were excluded. Patient's demographic data, laboratory results, medications, endoscopy and radiology reports were collected. Clinically relevant outcomes of the study included 28-day mortality and red cell transfusion requirement. Multivariable logistic regression analysis was used to identify factors independently associated with outcomes.

Results 130 patients (Median Age 73; male predominance $68 \%$ ) were included in the study after excluding readmissions $(\mathrm{n}=8)$ and UGI bleedings $(\mathrm{n}=9) .51 \%$ had major comorbidity, $37 \%$ taking antiplatelets and 25\% taking anticoagulants. $60 \%$ received blood transfusion and $31 \%$ required intervention (endoscopic therapy $(n=17)$, mesenteric embolization $(n=18)$ and surgery $(n=5))$. $72 \%$ had diagnostic endoscopy on admission with the majority being flexible sigmoidoscopy $(n=74)$. Median Length of hospital stay was 6 days, and 12\% experienced rebleeding on the same admission. 10 patients died within 28 days of admission. Low Haemoglobin $(p=0.027)$, raised C-reactive protein $(\mathrm{CRP})(\mathrm{p}=0.047)$ and no endoscopy performed on admission $(p=0.014)$ were associated with 28 day mortality. Low Haemoglobin $(\mathrm{p}<0.0001)$ was also significantly associated with red cell transfusion requirement.

Conclusions In our study, the majority of patients who were admitted with severe ALGIB were elderly with a high burden of co-morbidities and frequent antithrombotic use. Nevertheless, antithrombotic medication and co-morbidities were not significantly associated with mortality or red cell transfusion requirement.

\section{IDDF2020-ABS-0082 LIGHT WEIGHT PROLENE MESH WAS ASSOCIATED WITH LOWER INCIDENCE OF MESH REJECTION ON INGUINAL HERNIA UNDERGOING OPEN EMERGENCY HERNIA SURGERY}

${ }^{1}$ Budhi Ida Bagus*, ${ }^{2}$ Metria Ida Bagus, ${ }^{3}$ Setyawati Ida Ayu, ${ }^{1}$ Soewoto Widyanti, ${ }^{1}$ Wibisono Wibisono, ${ }^{1}$ Setyono Hanis, ${ }^{1}$ Ismail Darmawan, ${ }^{1}$ Yuli Yarso Kristanto. ${ }^{1}$ Department of Surgery, Sebelas Maret University, Indonesia; ${ }^{2}$ Medical Faculty, Sebelas Maret University, Indonesia; ${ }^{3}$ Medical Faculty, Pendidikan Ganesha University, Indonesia

\subsection{6/gutjnl-2020-IDDF.66}

Background Incarserated hernia was one of the most common procedures in gastrointestinal surgery. According to the latest Hernia Guidelines 2018, emergency hernia surgery has been suggested to used mesh in cases without contamination, whether we did by laparoscopic or open conventional procedures, but there was lack of data and recommendation, which kind of mesh should we used which could reduce the incidence of mesh rejection during emergency hernia surgery.

Methods Incarserated hernia cases which have been done open conventional hernia repair procedure (Lichtenstein procedure) were included in this study during Januari-December 2019. The patients were divided into two groups; the first group would use light-weight prolene mesh and the other one using heavy-weight mesh. The outcome that would be evaluated was the incidence of mesh rejection during those procedures after 6 months follow up. The cases with the presence of contamination would be excluded from this study.

Results 45 patients were included in this study, 24 patients with light-weight prolene mesh following Lichtenstein procedure and 21 patients using the heavy-weight mesh. During the follow-up, there was no drop out of the patient, and during 5 months follow up, we found 1 case of mesh rejection, 2 months after those procedures using heavy-weight mesh and had been managed by the operative procedure for debridement of the mesh rejection. On the other hand, we found no mesh rejection on light-weight mesh group $(\mathrm{p}<0.05)$.

Conclusions Light-weight prolene mesh was associated with a lower incidence of mesh rejection during open emergency hernia surgery.

\section{IDDF2020-ABS-0083 THE LENGTH OF STAY DIFFERENCE BETWEEN OPEN CONVENTIONAL VS LAPAROSCOPY CHOLECYSTECTOMY ON CALCULOUS CHOLECYSTITIS PATIENTS IN THE CURRENT GOVERNMENT INSURANCE ERA}

${ }^{1}$ Budhi Ida Bagus*, ${ }^{2}$ Metria Ida Bagus, ${ }^{3}$ Setyawati Ida Ayu, ${ }^{4}$ Mastini Ida Ayu Kade. ${ }^{1}$ Department of Surgery, Sebelas Maret University, Indonesia; ' 2 Medical Faculty, Sebelas Maret University, Indonesia; ${ }^{3}$ Medical Faculty, Pendidikan Ganesha University, Indonesia; ${ }^{4}$ Clincal Pharmacy Department, Moewardi General Hospital, Indonesia

\subsection{6/gutjin-2020-IDDF.67}

Background For the last two decades, laparoscopy cholecystectomy has been announced as the gold standard procedure for symptomatic cholelithiasis, and calculous cholecystitis with the main benefits was less post-operative pain and shorter length 
of stay. In other ways, for some other reasons, especially in our national government insurance, we could not perform those procedures in tertiary hospital as a routine procedure.

Methods In this retrospective study, we would evaluate, the length of stay difference between open conventional and laparoscopy cholecystectomy on calculous cholecystitis patients from January until December 2017. The length of stay after these procedures would be recorded. All patients had the same prophylactic antibiotic (2 gram of Cefazolin iv) and 1 gram Paracetamol iv twice daily. The patients who have been done the conversion to open cholecystectomy would be excluded from this study.

Results 94 calculous cholecystitis cases were evaluated in this study during 1 year period. 71 cases have been done open conventional cholecystectomy, 23 cases have been performed laparoscopy cholecystectomy. The mean length of stay on the open arm was 1.7 days, and 1.5 days for laparoscopy cholecystectomy. 3 patients on the open conventional arm had biliary pancreatitis and empyema gall bladder, and that case has a longer length of stay (3 days). There was no post-operative complication recorded.

Conclusions There was no length of stay difference between open conventional and laparoscopy cholecystectomy on calculous cholecystitis patients.

\section{IDDF2020-ABS-0084 COMPARISON OF 1L ADJUVANT AUXILIARY PREPARATIONS WITH 2L SOLELY POLYETHYLENE GLYCOL PLUS ASCORBIC ACID REGIME FOR BOWEL CLEANING: A META-ANALYSIS OF RANDOMIZED, CONTROLLED TRIALS}

${ }^{1}$ Xin Yuan*, 'Zhixin Zhang, ${ }^{1}$ Jiarong Xie, ${ }^{2} Y u$ Zhang, ${ }^{3}$ Lu Xu, ${ }^{2}$ Weihong Wang, ${ }^{2}$ Lei Xu. ${ }^{1}$ College of Medicine, Ningbo University, China; ${ }^{2}$ Department of Gastroenterology, Ningbo First Hospital, China; ${ }^{3}$ Clinical Department for Intensive Care, Ningbo Second Hospital, China

\subsection{6/gutjnl-2020-IDDF.68}

Background The effectiveness of additional usage of adjuvants for bowel preparation is still unclear. This study compared $1 \mathrm{~L}$ polyethylene glycol plus ascorbic acid with adjuvant drug regimens (1L-PEG-AA, lower-volume) with $2 \mathrm{~L}$ polyethylene glycol plus ascorbic acid (2L-PEG-A, low-volume) to evaluate whether the adjuvants can be used to reduce the standard dosage of purgative further.

Methods The PubMed/MEDLINE, EMBASE, Cochrane Library and Web of Science database were searched up to March 2020 for randomized controlled trials (RCTs). The primary outcome was the efficacy of bowel preparation, and the secondary outcomes were patients' tolerability and complication rate. The relative risk (RR) and mean difference (MD) with 95\% confidence intervals (CI) were pooled for dichotomous and continuous variables separately. The overall quality of evidence was assessed using the GRADEpro guideline development tool.

Results Five RCTs with a total of 1013 patients were included, and the majority of patients were outpatients from different hospitals. The pooled data showed no significant difference in the adequate bowel preparation rate $(89.3 \%$ versus $89.4 \%$, RR 1, 95\%CI $0.95-1.05, \mathrm{I}^{2}=47 \%$ ) (figure $1 \mathrm{~A}$ ) as well as in the complication rate (RR for nausea $1.22,95 \% \mathrm{CI}$ $0.89-1.65, \mathrm{I}^{2}=49 \%$; RR for bloating 0.96 , 95\%CI $0.73-1.28$, $\mathrm{I}^{2}=0 \%$; RR for vomiting 0.69 , 95\% CI $0.32-1.50, \mathrm{I}^{2}=33 \%$;

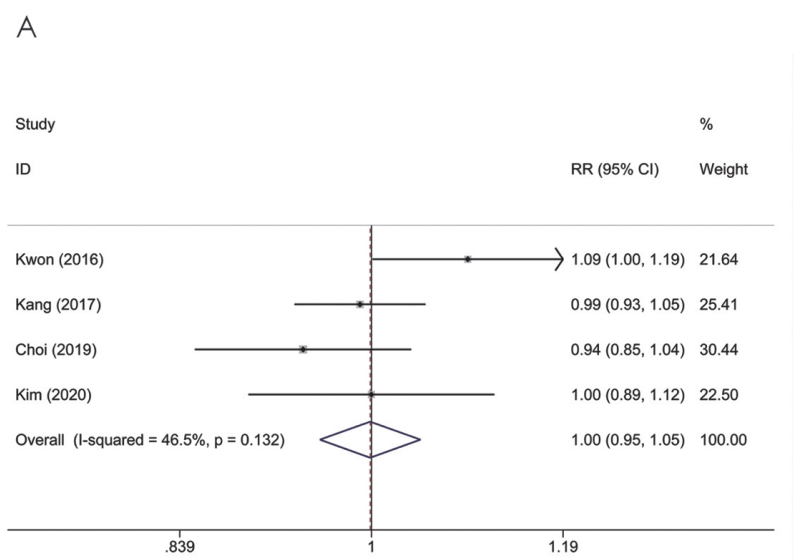

Abstract IDDF2020-ABS-0084 Figure 1A Forest plot on the efficacy and willingness between 1L-PEG-AA and 2L-PEG-A

B

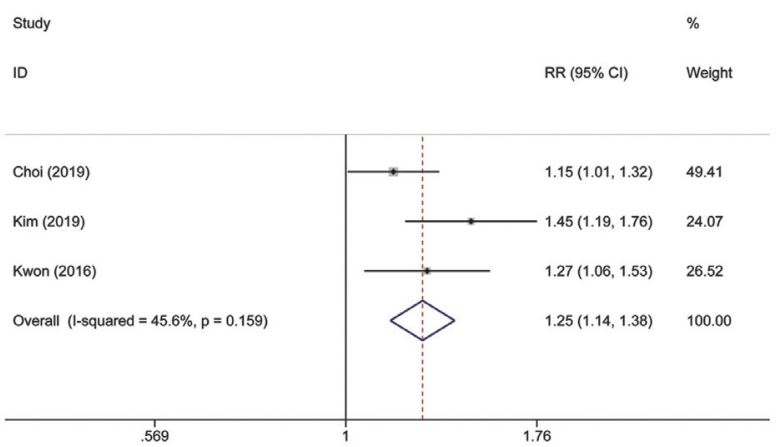

Abstract IDDF2020-ABS-0084 Figure 1B Forest plot on the efficacy and willingness between 1L-PEG-AA and 2L-PEG-A

RR for abdominal pain 1.01, 95\%CI 0.61-1.69, $\mathrm{I}^{2}=0 \%$ ). But a significantly higher willingness rate was observed in the lower-volume $(85.1 \%$ versus $67.9 \%$, RR 1.25 , 95\%CI 1.14 $1.38, \mathrm{I}^{2}=46 \%$ ) (figure $1 \mathrm{~B}$ ). The quality of primary outcome evidence was moderate.

Conclusions The findings of this meta-analysis revealed that 1L-PEG-AA might be a viable alternative to 2L-PEG-A, with comparable effectiveness, better patient preference, and no statistically significant adverse event occurrence.

\section{IDDF2020-ABS-0085 UNDERWATER VERSUS CONVENTIONAL ENDOSCOPIC MUCOSAL RESECTION FOR SMALL SIZE NON-PEDUNCULATED COLORECTAL POLYPS: A RANDOMIZED CONTROLLED TRIAL}

${ }^{1}$ Zhixin Zhang ${ }^{*},{ }^{2}$ Yonghong Xia, ${ }^{3}$ Hongyao Cui, ${ }^{1}$ Xin Yuan, ${ }^{4}$ Chunnian Wang, ${ }^{1}$ Jiarong Xie, ${ }^{2}$ Yarong Tong, ${ }^{5}$ Weihong Wang, ${ }^{5}$ Lei Xu. ${ }^{1}$ College of Medicine, Ningbo University, China; ${ }^{2}$ Department of Gastroenterology, Ninghai Second Hospital, China; ${ }^{3}$ Department of Gastroenterology, Haishu Second Hospital, China; ${ }^{4}$ Ningbo Clinical and Pathological Diagnosis Center, China; ${ }^{5}$ Department of Gastroenterology, Ningbo First Hospital, China

\subsection{6/gutjnl-2020-IDDF.69}

Background Underwater endoscopic mucosal resection (UEMR) is a recently developed technique and is performed during 